\title{
Effect of Occlusal Splints on the Stress Distribution on the Temporomandibular Joint Disc
}

Fabiane Maria Ferreira ${ }^{1,2}$, Paulo Cézar Simamoto-Júnior ${ }^{1}$, Carlos José Soares 3 , António Manuel de Amaral Monteiro Ramos ${ }^{4}$, Alfredo Júlio Fernandes-Neto ${ }^{1}$

\begin{abstract}
Conservative approach, including occlusal splint therapy, is the first option to treat temporomandibular disorders (TMD), because of its reversibility. The present study analyzed the effect of the articular disc position and occlusal splints use on the stress distribution on this disc. A two-dimensional (2D) finite element (FE) model of the temporomandibular joint with the articular disc at its physiologic position was constructed based on cone-beam computed tomography. Three other FE models were created changing the disc position, according to occlusal splint use and anterior disc displacement condition. Structural stress distribution analysis was performed using Marc-Mentat package. The equivalent von Mises stress was used to compare the study factor. Higher stress concentration was observed on the intermediate to anterior zone of the disc, with maximum values over $2 \mathrm{MPa}$. No relevant difference was verified on the stress distribution and magnitude comparing disc positions and occlusal splint use. However, there was stress reduction arising from the use of the occlusal splints in cases of anterior disc displacement. In conclusion, based on the generated FE models and established boundary conditions, the stress increased at the intermediate zone of the TMJ disc during physiological mandible closure. The stress magnitude was similar in all tested situations
\end{abstract}

\author{
'Department of Occlusion, Dental \\ School, UFU - Universidade Federal de \\ Uberlândia, Uberlândia, MG, Brazil \\ 2Department of Oral Rehabilitation, \\ Dental School, University of Rio \\ Verde, Rio verde, GO, Brazil \\ 3Department of Operative Dentistry, \\ UFU - Universidade Federal de \\ Uberlândia, Uberlândia, MG, Brazil \\ ${ }^{4}$ Department of Mechanical \\ Engineering, Biomechanics \\ Research Group, Universidade \\ de Aveiro, Aveiro, Portugal
}

Correspondence: Paulo Cézar Simamoto Júnior, Av. Pará, 1720, Bloco 4LA, Sala 4LA32, Umuarama, 38400-902 Uberlândia, MG, Brasil. Tel: +55-34-3225-8105. e-mail: psimamoto@foufu.ufu.br

\author{
Key Words: temporomandibular \\ joint, temporomandibular \\ joint disc, occlusal splints, \\ finite element analysis.
}

\section{Introduction}

Anatomically, between the condyle and the articular fossa of the temporomandibular joint (TMJ) there is the articular disc, a fibrocartilage that facilitates movement between the mandible and temporal bone (1). The main function of the articular disc is to absorb and distribute the load effect over a larger contact area to prevent damage to the articulating surfaces (1). This is important to maintain the stomatognathic system healthy, preventing articular disc alterations that may lead to temporomandibular disorders (TMD) (1).

The therapeutic approach required for TMJ treatment involves two categories: the conservative and surgical methods (2). Conservative methods, which involve occlusal splints, physical therapy, feedback, acupuncture and short-term pharmacotherapy, are the first option for TMJ treatment, because of their reversible nature (3). Occlusal splint therapy has frequently been used for internal derangement and myofascial pain treatment (2). The performance of the occlusal splint is based on the mechanism of neuromuscular reflex (4) and decrease of intra-articular pressure in TMJ (5).

Mandibular movement analysis has shown that sliding and rotating with slight lateral excursion occur simultaneously between articulating surfaces, the articular disc is subjected to many different loading regions (6). Compression, tension and shear loads can be observed, but combinations of these basic types of loading during physiological function of the joint are more common $(6,7)$. The TMJ disc consists of circumferentially and anteroposteriorly aligned collagen fibers, resulting in a tissue that is anisotropic under tension, shear stress and strain (8). The biomechanical behavior of the TMJ disc has not yet been understood completely and for this reason there are still no universally agreed values for TMJ loading conditions, either for maintenance or hazard $(7,9)$. In finite element analysis (FEA) of the TMJ studies have characterized the articular disc as isotropic elastic material, porohyperelastic, hyperelastic and viscoelastic (10-13)

Experimental tests to measure stresses and strains in the articular disc during loading are very difficult to conduct, due to the risk of biological damage to the joint (1). The FEA is nowadays the most appropriate method for investigating stress and strain distributions in the TMJ during mastication (1,9-14). Some studies simulated physiological mandibular movements or simulated prolonged teeth clenching $(9,12)$. Increase in the frictional coefficient between the articular surfaces may be a major cause of the onset of disc displacement (9). Continuous lateral movement of the jaw may lead to perforations in the lateral part of both discs, and may damage the lateral attachments of the disc to the condyle (12).

Generating a model of the masticatory system with 
anatomic characteristics close to reality is not a simple process. The literature is not clear about reference values for tissue properties, due to the diversity of characterizations found to articular disc (10-13). The degree of simplification of the model is difficult to establish, because computational and time limitations do not allow the masticatory system to be modeled in all its known complexity (13). Nevertheless, in recent years an improvement has been noted in TMJ representation for optimizing assessment of the physiological and pathologic strains in the joint disc (15), but further developments are still needed.

In this context, the aim of this study was to develop 2D computational models of normal TMJ and with anterior disc displacement, in order to simulate mandible closure in presence or absence of an occlusal splint. The null hypothesis was that the stress in the articular disc would be the same on all situations.

\section{Material and Methods \\ Finite Element Model Generation}

This study was approved by Ethics Committee (83073/2014), prior to study start. The TMJ geometry was obtained from cone-beam computed tomography (CT) of the right TMJ of an adult female volunteer (aged 28 years) with no history of present or past TMJ disorders. Four hundred thirty-two slices of the skull and mandible and images with a resolution of $0.2 \times 0.2 \times 0.2 \mathrm{~mm}$ voxels were obtained. From these images were delimitated the mandibular condyle and articular fossa-eminence of temporal bone contours. The upper and lower boundaries of the disc were modeled according to the upper and lower articular surfaces (Fig. 1). In this image, it was possible to identify the three parts of the articular disc: posterior zone, intermediate zone and anterior zone. The contours of the TMJ components were entered into MSC.Marc (MSC Software Corporation, Santa Ana, CA, USA) and 2D
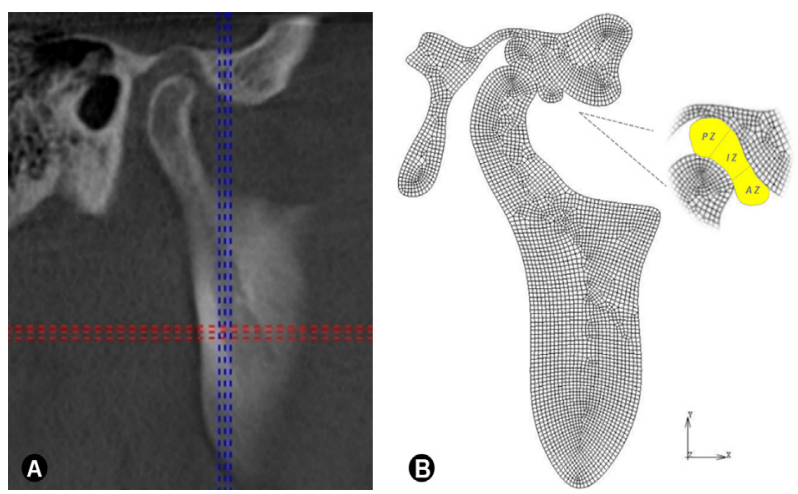

Figure 1. A: CT scan image of section; B: Numerical model and division of the articular disc into three parts: posterior, intermediate and anterior zones. quadric elements with four nodes were used. Bones and articular disc were discretized into 3,841 and 160 elements respectively. The mesh adaptive procedure was applied after each $0.1 \mathrm{~s}$ step.

From this model of normal TMJ, three other models were designed, considering the presence or absence of occlusal splints and presence or absence of anterior displacement of the articular disc. For this purpose, the volunteer also was submitted to a CT scan wearing occlusal splints. The images of this $\mathrm{CT}$ scan were analyzed to measure the upper distance (D1) and anterior distance (D2) of the joint space between the condyle surface and fossa (Fig. 2). The following changes were identified: a small increase in the upper joint space and decrease in the previously measured distance together with a slight rotation of the condyle, due to the $2 \mathrm{~mm}$ thick occlusal splints in the molar.

These changes agreed with another study that found similar changes in joint space during the use of mouthguards (16). Thus, compared with the original model, the condyle was moved downward and forward $0.4 \mathrm{~mm}$ and $0.2 \mathrm{~mm}$, respectively, to create models with occlusal splint use.

In order to create models with anterior disc displacement, the authors considered the concept that when the disc posterior band assumes an anterior position to the top of the mandibular condyle in the closed-mouth position, and the limit between disc and retrodiscal tissue is located anterior to the 11:30 clock position, this is considered anterior displacement of the disc (17). Based on this principle, in this study the disc was displaced anteriorly, compared with the original model.

Four FE TMJ models were created: (A) TMJ with normal

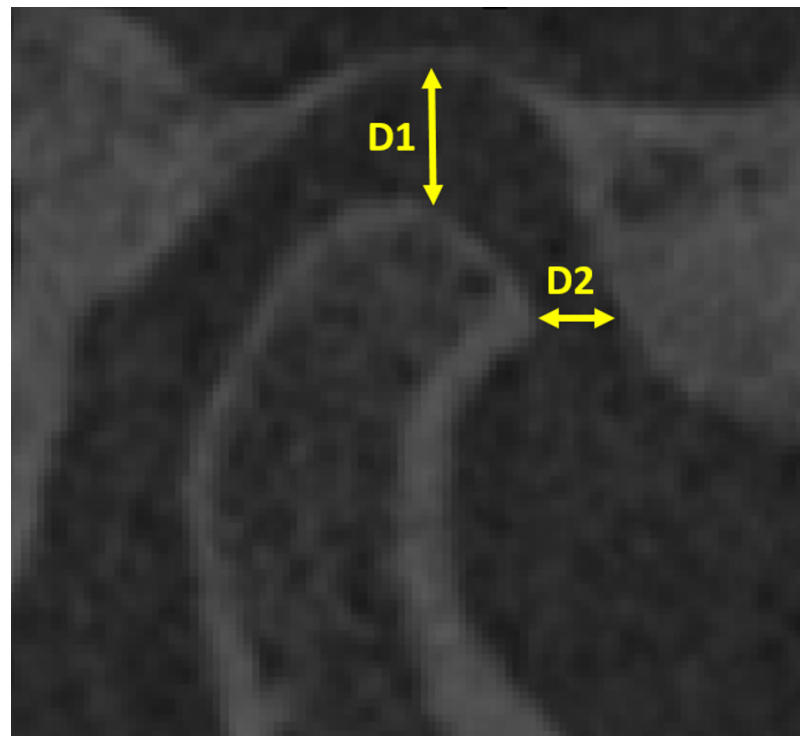

Figure 2. Measurement of the intra-articular spaces between surface of the condyle and the roof of the fossa-articular eminence. D1: upper distance; D2: anterior distance. 
disc position and without occlusal splint use; (B) TMJ with normal disc position and with occlusal splint use; (C) TMJ with anterior disc displacement and without occlusal splint use; (D) TMJ with anterior disc displacement and with occlusal splint use.

\section{Boundary Conditions}

The model was restricted to the area of the temporal bone on all degrees of freedom, and all structures were modeled as deformable bodies. The mechanical behavior of the bone structures was described with a linear isotropic elastic model. The material properties used in this study were obtained from the literature (Table 1) (11). Cortical bone properties were considered for temporal and mandibular bones. The articular disc was treated as an incompressible hyperelastic material and the classical Mooney-Rivlin form was used in this study. Thus, the strain energy equation was calculated by:

$$
U=\mathrm{C}_{1}\left(I_{1}-3\right)+\mathrm{C}_{2}\left(I_{2}-3\right)
$$

where $U$ was the strain energy density, $I_{1}$ and $I_{2}$ were the first and second deviatory strain invariants, and $C_{1}$ and $C_{2}$ were material constants determined from the non-linear

Table 1. Material properties of FEA models

\begin{tabular}{lcccc}
\hline Material properties & $v$ & $\mathrm{E}(\mathrm{MPa})$ & $\mathrm{C}_{1}(\mathrm{MPa})$ & $\mathrm{C}_{2}(\mathrm{MPa})$ \\
\hline Bones & 0.3 & 13700 & - & - \\
Articular disc & - & - & $9 \times 10-1$ & $9 \times 10-4$ \\
\hline
\end{tabular}
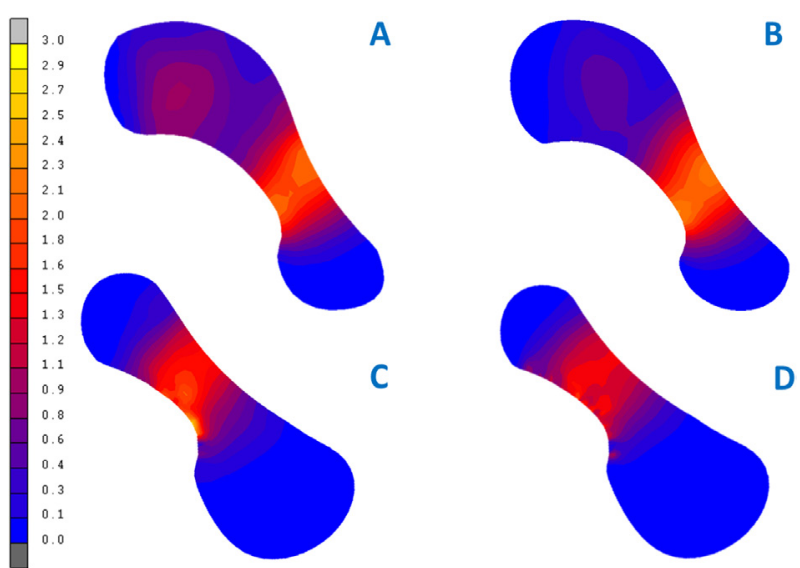

Figure 3. Von Mises stress distribution in the temporomandibular joint (TMJ) after mandibular closure, in the last increment and in the different models. A: TMJ with normal disc position and without occlusal splint use; B: TMJ with normal disc position and with occlusal splint use; C: TMJ with anterior disc displacement and without occlusal splint use; D: TMJ with anterior disc displacement and with occlusal splint use. stress-strain curves (18).

The joint was also considered well lubricated, so a friction coefficient of 0.0001 was considered between the disc and both bone structures (12). Simulation began with a closure of the mandible against the temporal bone in a direction corresponding to the estimated direction of the joint reaction force (19). For a mandible closure simulation, a displacement of $0.2 \mathrm{~mm}$ was applied for $1 \mathrm{~s}$ in the vertical direction (Axis Y). This simulation was on the response of the articular disc during clenching, similar to a previous study (20), corresponding to the simplest loading condition of the temporomandibular joint.

The mesh remodeling function was activated for the disc to perform the geometry of the bone in the fossa and in the condyle. The stress distribution in the disc was analyzed by Equivalent von Mises Stress, during $0.2 \mathrm{~mm}$ of mandibular closure, in 1, 5 and 10 increments. Other stresses and strains were performed on the superior and inferior surfaces of the articular disc, considering 27 nodes in the direction from posterior to anterior zone on each surface, after complete mandible closure.

\section{Results}

The stress distribution in normal disc position and without occlusal splint is presented in Figure 3A. There was stress concentration on the intermediate to anterior zone of the disc with over 2MPa maximum values .

During all mandibular closure there was different stress distribution in the anterior, intermediate and posterior zone of the disc (Fig. 1). Figure 4 shows representative nodes in anterior, intermediate and posterior zone of the disc. The most critical region was the intermediate zone, with values exceeding $2 \mathrm{MPa}$.

Total strain and equivalent von Mises stress on both surfaces (inferior and superior) in the four situations are presented in Figures 3 to 6 . The strain values on the inferior

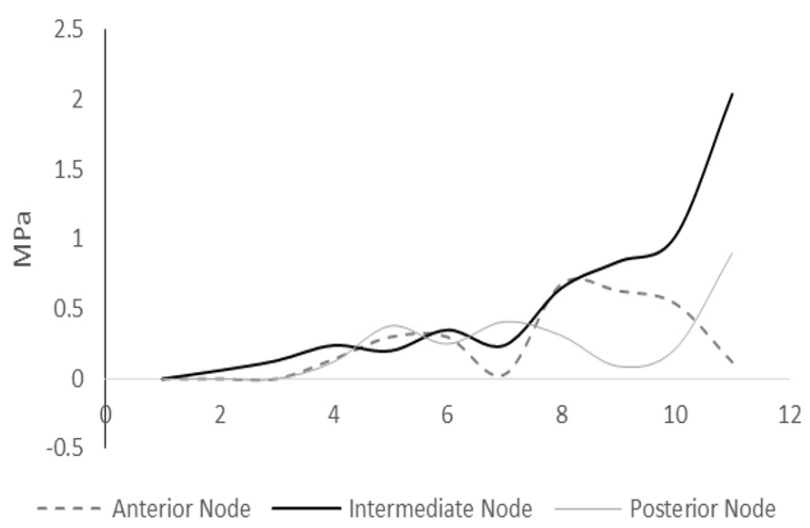

Figure 4. Von Mises stress variation in representative nodes in the disc during mandibular closure. 
surface and superior surface were analyzed in the final step (Fig. 5). Equivalent total strain was recorded in these nodes after complete mandible closure. The strain on the inferior surface was more critical than on the superior surface.

No differences in the intensity and location of the stress were observed when the disc was in normal position compared to with and without the occlusal splint. Lower stress values were observed in the TMJ with anterior disc displacement if associated with occlusal splint. When the disc was displaced, the highest stress was observed in its region between the intermediate and posterior zones (Fig. 6).

\section{Discussion}

The null hypothesis of this study was accepted, because the stress in the articular disc was similar in all tested situations. The model generated in this study had a good representation of the TMJ structures, since it presented feasible results compared with a previous study, where the disc was treated as an incompressible hyperelastic material, in the classical Mooney-Rivlin form (11).

Different models have been used to characterize the mechanical properties of the disc. Poroelastic and biphasic models are widely used to represent hyaline cartilages and some studies have used them to describe the articular disc $(12,20)$. However, this is probably not the best option for modeling the mechanical response of the TMJ disc, because the concentration of glycosaminoglycans (GAGs) in this fibrocartilaginous soft tissues is lower, which may result in reduced drag between the fluid and solid matrix (21).

The articular disc was shown to have both viscoelastic and hyperelastic properties and undergoes large deformation (22). Therefore, another form of representation is to consider soft tissues as viscoelastic structures. While it may be an oversimplification to assume the behavior of cartilaginous tissue to be only viscoelastic, for the purpose of a quantitative analysis of TMJ stress, it can allow a good qualitative study to be conducted (14). In this study, the hyperelastic Mooney-Rivlin material model was applied because it behaves most reliably under large deformations. Its hyperelasticity, however, is mainly directed to stretching. On the other hand, the compressive hyperelasticity of cartilage is still underrated (11). In this context, it was observed that there are many ways to represent the disc, but each has limitations that should be carefully considered in the interpretation of results.
A

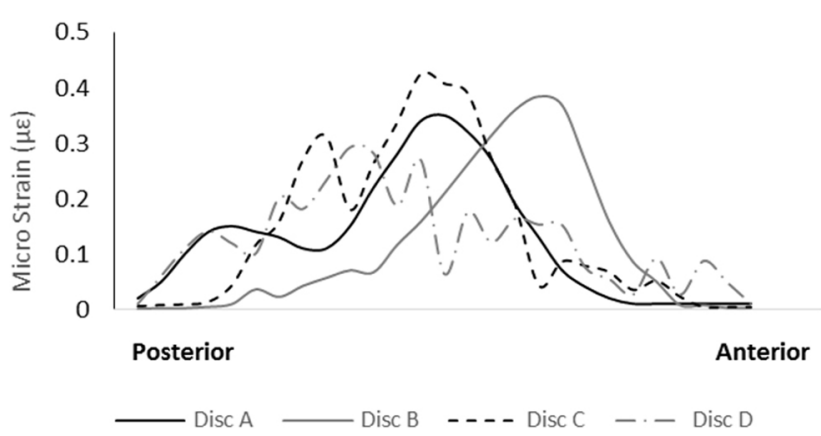

B

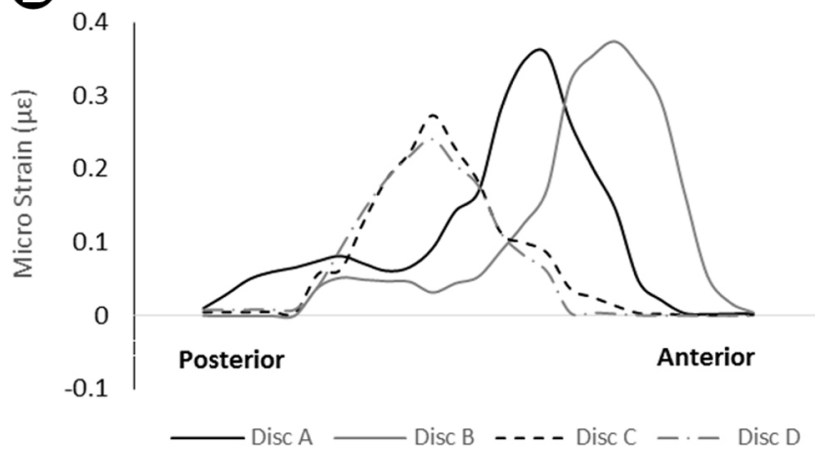

Figure 5. Equivalent of total strain distribution on the inferior (A) and superior (B) surfaces of the articular disc, after complete mandibular closure.

A

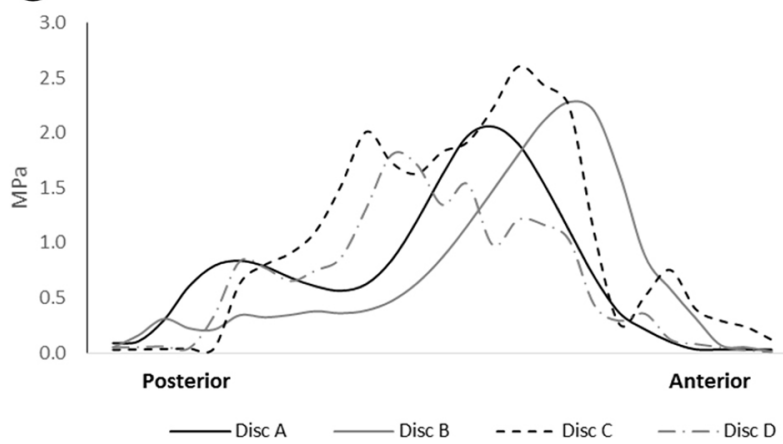

B

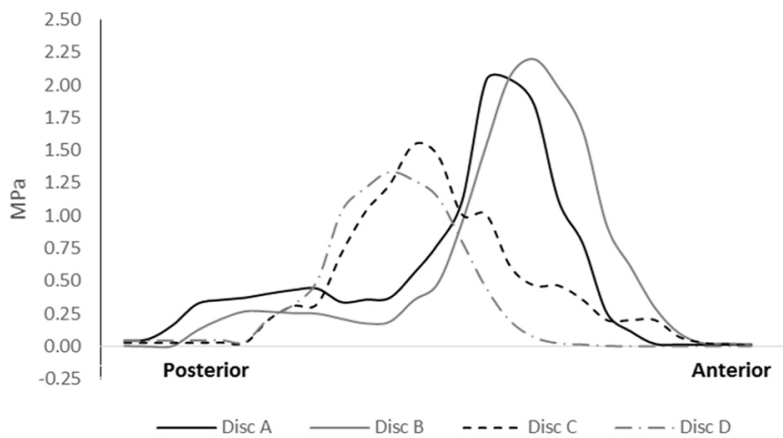

Figure 6. Equivalent Von Mises stress distribution on the inferior (A) and superior (B) surfaces of the articular disc, after complete mandibular closure. 
Maximum peak of the von Mises stress observed in the intermediate zone was also mentioned in previous studies $(10,11,14,22)$. And an anatomical study with a cadaver showed maximum pressure signals during mandibular movements in discs located in the intermediate zone (23). Von Mises analysis may represent predominantly shear stress (14), and this type of stress probably occurs because the joint surfaces and disc are not parallel during compression. As a result, not all areas of the disc undergo deformation in the same direction, leading to local shear stress (24). Another reason why shear stress occurs in the disc is its non-homogeneous structure (7). In long term, the mechanical properties of the disc may be impaired, since excessive shear stresses can cause fatigue and structural damage to the disc (24).

The anterior zone showed decreasing stress at the end of the mandibular closure. The maximum stress (0.68 MPa) in this region occurred at increment 7 , reducing at each step. The stress decrease has been reported in other studies $(11,14)$. An explanation for this is the stress relaxation that occurs during progressive mandibular closure, which resulted in a reduction of the peak stress within the disc and in the strain energy dissipation (10). After stress relaxation, the dissipation of the stress/strain, the concentration of the excessive energy can lead disc to brake up and cause damage to the other TMJ components (24).

Stabilization occlusal splints allow bilateral, simultaneous and homogeneous occlusal contacts and increase slightly the vertical occlusal dimension. A recent literature review stated that the success of occlusal appliances is due to the basic mechanism of neuromuscular reflex and stress reduction in the TMJ (4). The result of the present study agrees with this statement. Although the stress reduction arising from the use of occlusal splints in the disc displacement cases was small, it should not be disregarded, because the analysis time was also short. This analysis simulated only mandibular closure, corresponding to the simplest loading condition of the temporomandibular joint. Further studies with varied times are required to simulate the condition of teeth clenching. The limitation of this study was absence of temporal and condylar cartilage layers and retrodiscal tissues, although this simplification did not impair accuracy of the data compared with other studies in the literature. However, future studies should simulate these structures, which are necessary to test other masticatory movements, like parafunctional habits.

Although good clinical outcomes have been observed with occlusal splints $(2,4)$, sometimes these devices are not able to correct the disc position (25). The improvement of the signs and symptoms appears to be due to the loss of elasticity, remodeling and adaptation of the posterior disc attachment. The articular disk is a firm but flexible structure and its morphology may be altered. If the disk is anteriorly chronically displaced, it probably undergoes irreversible morphologic changes losing the elasticity of the posterior band (25). The reduction in stress and strain noted in this study and described by up-to-date literature about use of occlusal splints, suggest that these devices can be a good alternative to protect the articular disc and prevent structural damage or progressive disorders, especially when there is disc displacement in the anterior position.

In conclusion, this study demonstrated than the FEA generated model and the established boundary conditions were suitable for physiological mandible closure simulations. The stress increased at the intermediate zone of the TMJ disc and stress magnitude was similar in all tested situations.

\section{Resumo}

Abordagens conservadoras, incluindo o uso de placas oclusais, são as primeiras opções de tratamento para disfunção temporomandibular (DTM), devido à sua reversibilidade. 0 presente estudo analisou o efeito da posição do disco articular e do uso de placa oclusal na distribuição de tensões no disco. Um modelo bidimensional (2D) de articulação temporomandibular (ATM) em posição fisiológica, foi desenvolvido para análise pelo método de elementos finitos, baseado em imagens de tomografia computadorizada do tipo cone-beam. Três outros modelos foram criados alterando a posição do disco de acordo com o uso de placa oclusal e condição de deslocamento anterior do disco. Uma análise estrutural da distribuição de tensões foi realizada no software Marc-Mentat, e equivalente Von Mises foi usado para comparar os fatores em estudo. Maior concentração de tensão foi observada na zona intermediária para a zona anterior do disco, atingindo valores máximos acima de $2 \mathrm{MPa}$. Nenhuma diferença relevante foi verificada na localização e magnitude das tensões quando comparadas as posições do disco e uso de placa oclusal. No entanto, houve pequena redução das tensões decorrente do uso de placa oclusal em caso de deslocamento anterior do disco. Conclui-se que mediante os modelos criados e condições de contorno estabelecidas, as tensões na zona intermediária do disco aumentam durante o fechamento mandibular fisiológico. A magnitude das tensões foi semelhante em todas as situações testadas

\section{Acknowledgements}

The authors are indebted to the Coordenação de Aperfeiçoamento de Pessoal de Nivel Superior (CAPES) for sandwich doctorate scholarshipand (5345-14-6), and Fundação de Amparo à Pesquisa do Estado de Minas Gerais (FAPEMIG) for financial support (APQ-02557-14).

\section{References}

1. Commisso MS, Martínez-Reina J, Ojeda J, Mayo J. Finite element analysis of the human mastication cycle. J Mech Behav Biomed Mater 2015;41:23-35.

2. Lee HS, Baek HS, Song DS, Kim HC, Kim HG, Kim BJ, et al.. Effect of simultaneous therapy of arthrocentesis and occlusal splints on temporomandibular disorders: anterior disc displacement without 
reduction. J Korean Assoc Oral Maxillofac Surg 2013;39:14-20.

3. Öz S, Gökçen-Röhlig B, Saruhanoglu A, Tuncer EB. Management of myofascial pain: low-level laser therapy versus occlusal splints. J Craniofac Surg 2010;21:1722-1728.

4. Miernik M, Więckiewicz W. The basic conservative treatment of temporomandibular joint anterior disc displacement without reduction--review. Adv Clin Exp Med 2015;24:731-735.

5. Nitzan DW. Intraarticular pressure in the functioning human temporomandibular joint and its alteration by uniform elevation of the occlusal plane. J OralMaxillofac Surg 1994;52:671-679.

6. Fernández $P$, Jesús Lamela $M$, Ramos $A$, Fernández-Canteli $A$, Tanaka $E$. The region-dependent dynamic properties of porcine temporomandibular joint disc under unconfined compression. J Biomech 2013;46:845-848.

7. Stanković $S$, Vlajković $S$, Bošković $M$, Radenković G, Antić V, Jevremović D. Morphological and biomechanical features of the temporomandibular joint disc: an overview of recent findings. Arch Oral Biol 2013;58:1475-1482.

8. Singh M, Detamore MS. Biomechanical properties of the mandibular condylar cartilage and their relevance to the TMJ disc. J Biomech 2009;42:405-417.

9. Tanaka E, Hirose M, Koolstra JH, van Eijden TM, Iwabuchi Y, Fujita R, et al.. Modeling of the effect of friction in the temporomandibular joint on displacement of its disc during prolonged clenching. J Oral Maxillofac Surg 2008;66:462-468.

10. Hirose M, Tanaka E, Tanaka M, Fujita R, Kuroda Y, Yamano E, et al.. Threedimensional finite-element model of the human temporomandibular joint disc during prolonged clenching. Eur J Oral Sci 2006;114:441-448.

11. Koolstra JH, van Eijden TM. Combined finite-element and rigid-body analysis of human jaw joint dynamics. J Biomech 2005;38:2431-2439.

12. Pérez Del Palomar $A$, Doblaré M. Finite element analysis of the temporomandibular joint during lateral excursions of the mandible. J Biomech 2006;39:2153-2163.

13. Gröning F, Fagan $M, O^{\prime}$ Higgins $P$. Modeling the human mandible under masticatory loads: which input variables are important? Anat Rec (Hoboken) 2012;295:853-863.

14. Mori $H_{1}$ Horiuchi $S$, Nishimura $S$, Nikawa $H$, Murayama $T$, Ueda $K$, et al.. Three-dimensional finite element analysis of cartilaginous tissues in human temporomandibular joint during prolonged clenching. Arch
Oral Biol 2010;55:879-886.

15. Savoldelli C, Bouchard PO, Loudad R, Baque P, Tillier Y. Stress distribution in the temporo-mandibular joint discs during jaw closing: a high-resolution three-dimensional finite-element model analysis. Surg Radiol Anat 2012;34:405-413.

16. Murakami S, Maeda Y, Ghanem A, Uchiyama Y, Kreiborg S. Influence of mouthguard on temporomandibular joint. Scand J Med Sci Sports 2008;18:591-595.

17. Ahmad M, Hollender L, Anderson 0 , Kartha K, Ohrbach R, Truelove EL, et al.. Research diagnostic criteria for temporomandibular disorders (RDC) TMD): development of image analysis criteria and examiner reliability for image analysis. Oral Surg Oral Med Oral Pathol Oral Radiol Endod 2009;107:844-860.

18. Chen J, Akyuz U, Xu L, Pidaparti RM. Stress analysis of the human temporomandibular joint. Med Eng Phys 1998;20:565-572.

19. Koolstra JH, van Eijden TM. Application and validation of a threedimensional mathematical model of the human masticatory system in vivo. J Biomech 1992;25:175-187.

20. Pérez del Palomar A, Doblaré M. The effect of collagen reinforcement in the behaviour of the temporomandibular joint disc. J Biomech 2006;39:1075-1085.

21. Allen KD, Athanasiou KA. Viscoelastic characterization of the porcine temporomandibular joint disc under unconfined compression. J Biomech 2006; 39:312-322.

22. Beek M, Aarnts MP, Koolstra JH, Feilzer AJ, van Eijden TM. Dynamic properties of the human temporomandibular joint disc. J Dent Res 2001;80:876-880.

23. Oberg $\mathrm{T}$, Carlsson GE, Fajers CM. The temporomandibular joint. A morphologic study on a human autopsy material. Acta Odontol Scand 1971;29:349-384.

24. Tanaka E, van Eijden T. Biomechanical behavior of the temporomandibular joint disc. Crit Rev Oral Biol Med 2003;14:138-150.

25. Choi BH, Yoo JH, Lee WY. Comparison of magnetic resonance imaging before and after nonsurgical treatment of closed lock. Oral Surg Oral Med Oral Pathol 1994;78:301-305.

Received December 13, 2016 Accepted February 23, 2017 